This item was submitted to Loughborough's Research Repository by the author.

Items in Figshare are protected by copyright, with all rights reserved, unless otherwise indicated.

\title{
The impact of the congestion charge on the retail business in London: an
} econometric analysis

PLEASE CITE THE PUBLISHED VERSION

PUBLISHER

(C) Elsevier

VERSION

AM (Accepted Manuscript)

LICENCE

CC BY-NC-ND 4.0

\section{REPOSITORY RECORD}

Quddus, Mohammed A., Michael G.H. Bell, Jan-Dirk Schmocker, and Achille Fonzone. 2019. "The Impact of the Congestion Charge on the Retail Business in London: An Econometric Analysis". figshare. https://hdl.handle.net/2134/5285. 
This item was submitted to Loughborough's Institutional Repository (https://dspace.lboro.ac.uk/) by the author and is made available under the following Creative Commons Licence conditions.

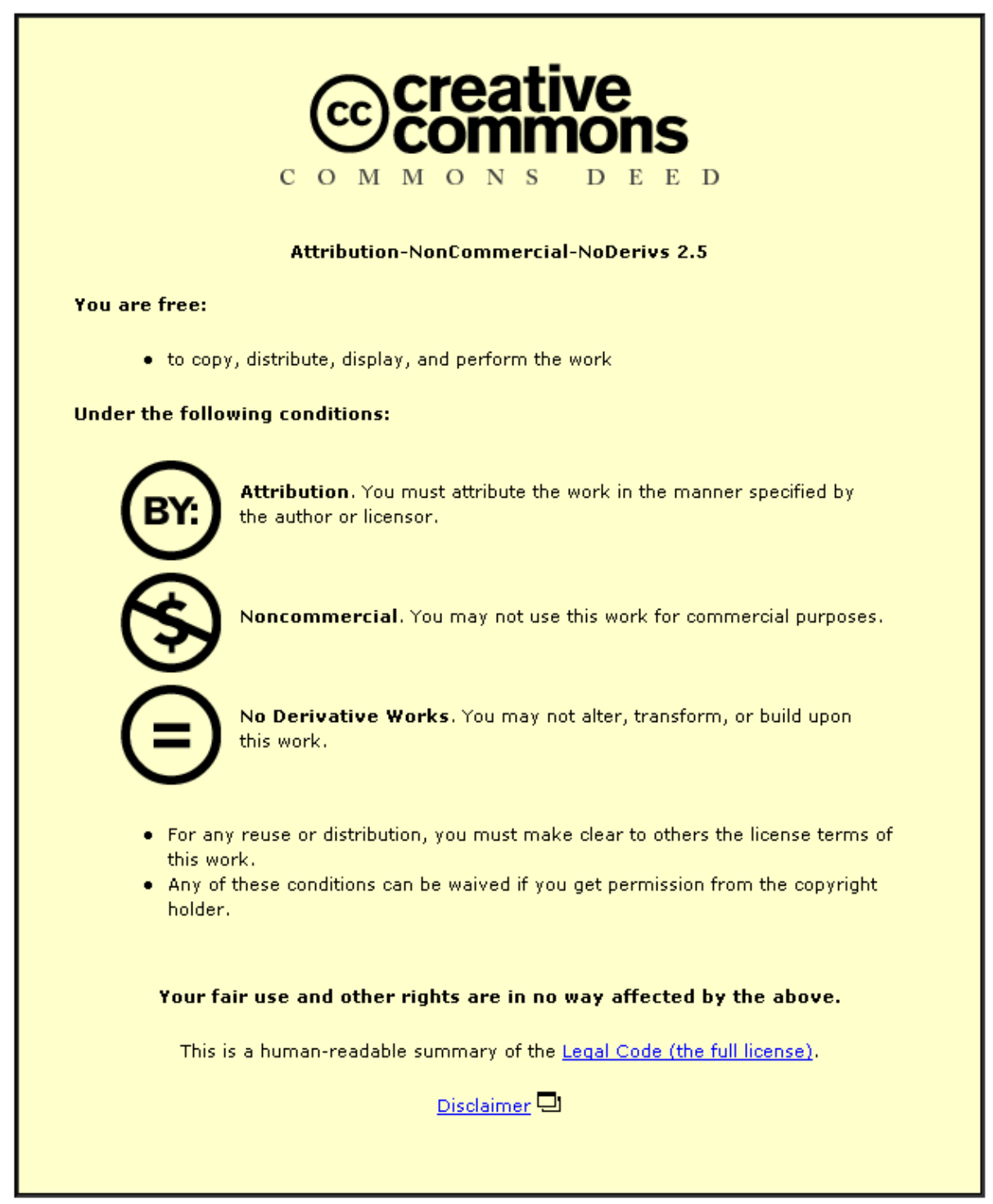

For the full text of this licence, please go to: http://creativecommons.org/licenses/by-nc-nd/2.5/ 
The Impact of the Congestion Charge on the Retail Business in London:

\title{
An Econometric Analysis
}

\author{
Mohammed A Quddus \\ Michael G H Bell \\ Jan-Dirk Schmöcker \\ Achille Fonzone
}

Centre for Transport Studies

Dept. of Civil \& Environmental Engineering

Imperial College London

London, SW7 2AZ

Email: m.quddus@imperial.ac.uk

Ph: +44(0)20-7594-6153

Fx: +44(0)20-7594-6102 


\begin{abstract}
On 17 February 2003, London introduced a pioneering congestion charging scheme. The impact on traffic was sudden and dramatic. For example, car movements within the congestion charging zone (21 square kilometer) were reduced by about 30\%. However, the impact on other activities, such as retail business within the charged zone, is taking longer to become evident. Many unusual events happened in close succession in 2003 making it difficult to isolate the effect of any individual event on the retail sales. This paper describes a detailed study on the impact of the congestion charge (CC) on the John Lewis Oxford Street (JLOS) store, which is one of the biggest retail stores within the charged zone. The impact is estimated using descriptive analysis, forecasting methods and econometric models. The analysis is based on weekly sales data for the period 30 January 2000 to 3 January 2004 (three years before the CC and about one year afterwards) relating to JLOS and five other John Lewis stores in and around London. A Seasonal Autoregressive Integrated Moving Average (SARIMA) model was fitted, showing that actual sales match predicted sales up to 19 January 2003 for the JLOS store but that actual sales fall consistently below predicted sales thereafter. Clearly something changed for the JLOS store during the week after 19 January 2003 with no sign of recovery to the end of the time series. In order to isolate the effects of a range of factors on sales, econometric models were fitted. The drop in sales at the JLOS attributable to the CC was found to be $5.5 \%$ by the time series model and $8.2 \%$ by the panel model (ceteris paribus).
\end{abstract}

Keywords: Congestion charge, Retail business, trend \& seasonality, Econometric models 


\section{Background}

On 17 February 2004 London introduced a pioneering congestion charging scheme. Vehicles present in a 21 square kilometre zone enclosing the core shopping, government, entertainment and business districts between 7:00 and 18:30 were subjected to a $£ 5$ per day charge (£8 from July 2005), unless they were eligible for a residents discount or were exempted. Exemptions were granted to environmentally friendly vehicles (battery powered or hybrid cars), motorcycles, disabled motorists (Blue Badge holders), taxis, buses and certain other categories deemed to be essential.

The impact on traffic was sudden and dramatic. According to Transport for London's own data (TfL, 2003), traffic in the zone has been reduced by 16\% (30\% for cars; motorcycle, taxi, bus and cycle traffic has increased). This translates into a 32\% reduction in congestion, measured in terms of delay per kilometre. Average traffic speeds have increased from $13 \mathrm{~km} / \mathrm{h}$ to $17 \mathrm{~km} / \mathrm{h}$. TfL (2003) estimates that the number of car trips into the zone has fallen by 150,000 per day, of which $10 \%$ to $20 \%$ are displaced through trips, $50 \%$ to $70 \%$ have shifted to public transport, and $20 \%$ to $30 \%$ went elsewhere (used other modes, travelled at other times or chose alternative destinations).

The impact on activities within the charged zone is taking longer to become evident. An early survey by the London Chamber of Commerce and Industry of its members found that 76\% of traders reported reduced takings year on year, of which more blamed the congestion charge (CC) than the Central Line (an important London Underground transit line that pass through the congestion charging area) closure, terrorist fear, economic downturn, or increasing competition from other sources (Winsor-Cundell, 2003). London First (2004) gives a more positive assessment, although in a recent press release it observed that "there may be sectors, especially 
retail and leisure, where the impact of the charge may not have been wholly positive”. Taking data up to June 2003, Carmel (2003) studied retail sales in central London. He found that the onset of the decline in sales predated the introduction of the CC and suggested that the most significant reasons are a general economic downturn, a fall in overseas visitors and the closure of the Central Line (CL). Schmöcker et al. (2004) show that the number of shopping trips to central London has declined since 2003 and that this is at least partly due to the introduction of the CC scheme.

According to Whitehead (2000), congestion charging is likely to have a positive impact on the retail sector of a city centre surrounded by charging cordon, but in the longterm only and primarily if money is reinvested in public transport and the improvement of the city centre environment. This study notes that it may take up to 20 years for the benefits to become fully visible. The research is based on a national survey in the U.K. of those within business, industry, government and academia who are thought to be very familiar with the process of economic change. Bonsall (2000) states that several cities have "commissioned studies to look at the possible impact of road pricing on their local economy”. Nevertheless Bonsall continues to show that in the past decisions whether to introduce congestion charging or not have been mainly focused on other issues. Policy makers expect benefits such as increased public transport usage, reduced travel times in the congestion charging zone as well as a better environment within the zone. Quddus et al. (2006) examine the impact of the charge on the retail sector as a whole in central London ${ }^{1}$ and the JL Oxford Street store in isolation. The results suggest that the charge had a significant impact on sales (down about $7 \%$ as a result of the charge) at the John Lewis

\footnotetext{
${ }^{1}$ Central London here is defined to coincide with the area covered by the London Retail Consortium's central London Retail Sales index. It includes Knightsbridge and High Street Kensington as well as the congestion charging zone.
} 
store on Oxford Street over the period studied but had no effect on overall retail sales in central London.

This paper revisits the question of the CC's impact on retail with a considerable quantity of retail sales data (both before and after the introduction of the CC) for the John Lewis (JL) stores inside and outside the charged zone. While Quddus et al. (2006) focused more on time-series analysis , this study applies panel data models to six JL branches in and around the charge zone. These are: John Lewis Oxford Street (JLOS), JL Peter Jones, JL Kingston, JL Bluewater (JLB), JL Brent Cross and JL Watford (Figure 1). The JL branches in London are linked by geographical proximity (Figure 1) allowing some customers to change shop relatively easily. The key advantage of using panel data over time series data or cross-section data is that they permit more general types of individual heterogeneity.

Additionally, this paper employs a seasonal Autoregressive Integrated Moving Average (ARIMA) model to forecast the sales for 2003 using sales data from 2000 to 2002. By taking into account both seasonality and trend, this model allows us to estimate the change of sales in 2003. The paper also employs UK-based economic data (e.g., GDP, overseas visitors) in stead of London-based data used in Quddus et al (2006).

\section{$<<$ Figure 1 about here $>>$}


With the exception of JL Bluewater (JLB) in which rapid growth of sales is observed over the last few years, all branches lie within the M25 motorway. As can be seen from Figure 1, only one JL branch, JL Oxford Street (JLOS), is located within the congestion charging zone. The fact that so many unusual events, such as the introduction of the CC, the closure of the CL, the Iraq War (IW) etc. happened in close succession in 2003 makes it difficult to isolate the effect of any individual event on the sales. The objective of this study is to test the hypothesis that the introduction of the CC on the $17^{\text {th }}$ February 2003 had a significant effect on the retail sales of JLOS store.

The paper is organized as follows. First we provide a brief descriptive analysis of the sales data for JLOS store. This is followed by a description of a Seasonal ARIMA (SARIMA) model to forecast sales for 2003 using sales data from 2000 to 2002. A brief description of the potential factors affecting retail activity is then presented. Econometric models, such as the loglinear model with autoregressive disturbance, AR(1), for time series data (individual stores) and a random effect loglinear model with AR(1) for panel data (all six stores) are then described, followed by a presentation of results. This is followed by conclusions.

\section{Descriptive analysis of sales data}

Although the aim of this study is to investigate the impact of the CC on the sales of the JLOS store, all six branches in and around London should be considered due to their geographical proximity (see Figure 1). Sales data for all six branches was therefore analysed for the period of $30^{\text {th }}$ January 2000 to $3^{\text {rd }}$ January 2004. This period includes three years before the CC and nearly one year afterwards. Within this time period, all JL branches were usually open from Monday to 
Saturday, but not Sundays and Public holidays. The stores do, however, have different opening hours. It was decided to end the period of analysis on $3^{\text {rd }}$ January 2004 because JL started to open their stores on Sundays from $4^{\text {th }}$ January 2004, making a before and after comparison of the impact of the CC more difficult as Sunday trading increases total weekly sales. Weekly sales data for the 6 branches in question for 205 weeks ( $30^{\text {th }}$ January 2000 to $3^{\text {rd }}$ January 2004) was obtained, leading to a cross-sectional $(N=6)$ time-series $(T=205)$ panel data set with a total of $1230(N \times T)$ observations.

\section{$<<$ Figure 2 about here $>>$}

The comparative time plot of weekly sales for JLOS between 2002 and 2003 is shown in Figure 2. Different events that occurred in 2003 are also indicated on the plot by arrow symbols. This plot also suggests that weekly sales in 2003 are consistently lower than 2002 sales. Retail sales are usually influenced by the Easter holidays. Sales are usually high just before Easter and low just after Easter. However, Easter changes from year to year, for example Easter Day was $31^{\text {st }}$ March in 2002 but $20^{\text {th }}$ April in 2003. The comparative time plot of weekly numbers of transactions for JLOS exhibits a similar pattern to the weekly sales, but is not showed here for brevity.

\section{$<<$ Figure 3 about here $>>$}

Figure 3 shows the comparative time plot of weekly sales per transaction for JLOS between 2002 and 2003. Weekly sales per transaction increase between late January and mid-April, 
perhaps due to the closure of the Central Line (CL) on the $25^{\text {th }}$ January 2003. The CL was fully reopened on the $2^{\text {nd }}$ June 2003. Usage of the CL does not return to pre-closure levels even after the line was fully reopened on $2^{\text {nd }}$ June 2003 (TfL, 2003), perhaps due to some commuters finding alternative routes to reach their destinations or changing their mode. A shift of passengers from tube to bus is plausible as bus speeds improved after the implementation of the CC (TfL, 2003).

During the period when the CL was most affected, weekly sales per transaction increased relative to 2002, probably because those who usually take public transport to get to Oxford Street generally purchase lower price items. The CL is one of the most important public transport services for Oxford Street with around 250,000 users of this service per day (TfL, 2003). As can be seen from Figure 3, weekly sales per transaction return to usual values beyond mid-April 2003.

\section{Seasonal ARIMA (SARIMA) model}

A time series forecasting model can be used to estimate the weekly sales for JLOS for 2003 by means of sales data from 2000 to 2002. A comparison between estimated sales and observed sales for 2003 can then be made.

The seasonal autoregressive integrated moving average (SARIMA) model, which is usually denoted by SARIMA $(p, d, q) \times(P, D, Q)_{S}$ model, is used to forecast weekly sales for 2003 . In this model, $p$ is the order of the non-seasonal autoregressive (AR) process, $P$ is the order of the seasonal AR process, $d$ is the order of the non-seasonal difference, $D$ is the order of the seasonal difference, $q$ is the order of the non-seasonal moving average (MA) process, $Q$ is the order of the 
seasonal MA process, and the subscript $s$ is the length of seasonality (for example $s=52$ in case of weekly time series data). A fuller description of the model could be found in Mills (1997).

Examining the auto-correlation function (ACF) and the partial auto-correlation function (PACF) of a time series can help to identify the values of each of these parameters.

\subsection{Results for John Lewis Bluewater}

A SARIMA model of the order $(0,1,1) \times(0,1,1)_{52}$ is initially identified. Since the residuals obtained from the ACF and PACF appear to be white noise and the coefficients for non-seasonal MA and seasonal MA are highly significant ( $t$ statistics are 25.66 and 2.69 respectively), the model can be accepted for forecasting weekly sales of JLB for 2003 (from $26^{\text {th }}$ January). The forecast sales can then be compared with the actual sales (see Figure 4). The sales forecast by the SARIMA model are broadly consistent with the observed sales.

\section{$<<$ Figure 4 about here $>>$}

\subsection{Results for John Lewis Oxford Street}

The time series of weekly sales for JLOS exhibits the same characteristics of ACF and PACF as for JLB. Hence the SARIMA $(0,1,1) \times(0,1,1){ }_{52}$ model may also be used to forecast weekly sales of JLOS. The comparison of observed and predicted sales is shown in Figure 5. The sales predicted for 2003 are lower than the observed sales. 
$<<$ Figure 5 about here $>>$

\section{Factors potentially affecting retail sales}

\subsection{The introduction of the congestion charging}

TfL (2003) stated that there has been a substantial reduction in cars, vans and lorries, with some increases in taxis, buses, pedal cycles and motorcycles. The report also stated that car movements have reduced by about $30 \%$, van and lorry movements have reduced by about $10 \%$, both taxi and motorcycles movements have increased by about 20\%, buses and coach movements have increased by about $15 \%$ and pedal cycle movements have increased by about $30 \%$ in Spring 2003 compared to Spring 2002. Substantial reductions in car trips within the charging zone may play a significant role in reducing retail activity in 2003. Both Winsor-Cundell (2003) and TfL (2003) reported concern about the possible impact of the CC on the retail sector.

\subsection{The closure of the central line}

The derailment of a London Underground train at Chancery Lane on $25^{\text {th }}$ January 2003 resulted in minor injuries to 32 people and led to the closure of the CL. It reopened for full services some 4 months later on $2^{\text {nd }}$ of June 2003, however there were lower frequency services from mid-March. It is worthwhile noting that the most affected period is $26^{\text {th }}$ January to mid- 
April. Since the closure of the CL and the introduction of the CC overlapped in time, both factors need to be considered in the analysis of JL retail sales.

\subsection{The economy}

Gross Domestic Product (GDP) provides a measure of the total economic activity in a region. Retail sales data, however, provides valuable information about consumer spending, the consumption part of GDP. The Office of the National Statistics, ONS (2003) has reported that the chained volume measure of national GDP increased by $0.9 \%$ in the fourth quarter of 2003 (2003Q4) compared with the previous quarter (2003Q3). For 2003 as a whole, this measure gives a $2.1 \%$ increase relative to 2002 . The volume of retail sales also exhibits a similar pattern. The index of retail sales at constant 2000 prices is 1.9\% higher in 2003Q4 compared with 2003Q3.

\subsection{The overseas visitors to the UK}

Overseas visitors to London may have an effect on retail sectors in central London. However, we do not have tourism data for London. Therefore, overseas visitors to the UK are used instead. Within the first three quarters of 2003, expenditure by UK visitors was about $£ 8.98$ billion ONS (2003). It was $£ 8.91$ billion for the same quarters in 2002. ONS (2003) also stated that visitors generally decreased in 2003 during the months of March, April and May compared to the same months of any previous years. This may be due to the influence of the Iraq War. 
However, over a longer period, in the 12 months ending November 2003, the number of visits by overseas residents to the UK rose by 4 per cent and spending increased by 3 per cent compared with a year earlier.

\subsection{Trend and seasonality}

The two main sources of variation in many time series data are seasonal variation and trend. Seasonal variation is annual in period and arises for many series, whether measured weekly, monthly or quarterly, when similar patterns of behaviour are observed at particular times of the year. For example, weekly sales at John Lewis Oxford Street store exhibit a seasonal variation (see Figure 2) since sales are usually high during the Christmas period. Trend is present in a time series when it exhibits either steady growth or decline, at least over several successive time periods (Chatfield, 1996).

\section{Econometric modelling of sales data}

As stated earlier, there are six JL branches in and around London, with large variations in sales among the branches over the years. An econometric model for each of the branches may be suitable to determine the impact of the CC on sales. However, the JL branches within London are linked by geographical proximity (see Figure 1), allowing some customers to change shop relatively easily. Therefore, a pooled model including sales data from all the London branches may be more appropriate. Two types of model are then considered in this study; one is a time series model for each branch and the other is a panel data model for all branches. 


\subsection{Econometric model form: time series model}

In the case of time series models, the dependent variable is the weekly sales of a particular branch and the explanatory variables with summary statistics are shown in Table 1. Approximately four years of weekly sales data is used to analyse sales for each of the JL branches. Since the introduction of the CC and the closure of the CL are qualitative variables, dummy variables are used to determine their association with sales.

\section{$<<$ Table 1 about here $>>$}

The dummy variable for the CC takes on a value of 1 for sales after $16^{\text {th }}$ February 2003 and a value of 0 otherwise. The dummy variable for the CL takes on a value of 1 for sales between $26^{\text {th }}$ January 2003 and $1^{\text {st }}$ June 2003, otherwise it takes on a value of 0. Data on GDP, exchange rate, overseas visitors and consumer price indices (CPI) are collected from the ONS (2003). Two commodity types, 'clothes and footwear' and 'furniture and household', are considered for the CPI in this analysis, since they constitute important sectors for JL.

A loglinear model with AR(1) given by

$$
\ln y_{t}=\alpha+\boldsymbol{\beta} \ln \boldsymbol{X}_{t}+\boldsymbol{\theta} \boldsymbol{D}_{t}+\varepsilon_{t}
$$

where the errors satisfy

$$
\varepsilon_{t}=\rho \varepsilon_{t-1}+\eta_{t}
$$


was selected to model time series data of individual stores. $y_{t}$ is the value of sales for period $t$ (say, week $t$ ), $\boldsymbol{X}$ is a $\mathrm{k} \times 1$ vector of continuous explanatory variables, $\boldsymbol{D}$ is a $\mathrm{m} \times 1$ vector of dummy explanatory variables, $\varepsilon$ is white noise, $\rho(-1<|\rho|<1)$ is the autocorrelation coefficient, and $\eta_{i t}$ is independent and identically distributed with zero mean and variance $\sigma^{2} \cdot \boldsymbol{\beta}$ and $\boldsymbol{\theta}$ are appropriately sized vectors of parameters to be estimated.

\subsection{Econometric model form: panel model}

Panel data are observations on a cross-section of units (usually heterogeneous in nature) such as JL stores, households or regions that are observed over a time period. A key advantage of panel data over cross-section data is that they allow a more general type of individual heterogeneity and hence more efficient estimation. For example, if the errors are correlated across stores, this should be allowed for in estimation. Two types of panel data model are frequently encountered in the literature. One is the fixed effects model while the other is the random effects model. In our case, a random effects model is more appropriate because it can accommodate covariates that are constant over time and therefore chosen. In this analysis, the same set of explanatory variables as for the time series models is used. The random effect loglinear model with $\operatorname{AR}(1)$ can be expressed as

$$
\ln Y_{i t}=\alpha+\boldsymbol{\beta} \ln \boldsymbol{X}_{i t}+\boldsymbol{\theta} \boldsymbol{D}_{i t}+v_{i}+\varepsilon_{i t}
$$

where

$$
\varepsilon_{i t}=\rho \varepsilon_{i, t-1}+\eta_{i t}
$$


in which $\boldsymbol{X}$ is a $\mathrm{k} \times 1$ vector of continuous explanatory variables, $\boldsymbol{D}$ is a $\mathrm{m} \times 1$ vector of dummy explanatory variables, $v$ is unit specific residual which is independently and identically distributed with zero mean and $\sigma_{v}^{2}$ variance, $\eta_{i t}$ is iid with zero mean and $\sigma_{\varepsilon}^{2}$ variance. As before, $\boldsymbol{\beta}$ and $\boldsymbol{\theta}$ are appropriately sized vectors of parameters to be estimated.

\subsection{Results for JLOS: time series model}

The problem of multicollinearity among explanatory variables is detected by Variance Inflation Factor (VIF) and tolerance test (Chattergiee et al., 2000). It is found that GDP and the trend variable are highly correlated. The PE test by Mackinnon et al. (1983) suggests that the linear model is rejected (but only at an 86\% confidence level) and the loglinear model is not rejected. The advantage of the loglinear model is the easy interpretation of the explanatory variables. Furthermore, the coefficients of the explanatory variables can be regarded as elasticities. Ramsey’s RESET test (Ramsey, 1969) is used to test for regression specification error. The test suggests that we can reject the hypothesis that the loglinear model is misspecified. Since JL weekly sales of a particular branch are a time series, heteroskedasticity is unlikely to be a feature. The Park Test (Park, 1966) confirms this.

\section{$<<$ Table 2 about here $>>$}

Therefore, the association of the weekly sales and the explanatory variables is established using a loglinear model with an AR(1) disturbance. The result is presented in Table 2 (the 
constant has been omitted to preserve confidentiality of the sales data). The model goodness-offit, the adjusted $R^{2}$, is 0.82 which is a very good fit. The interpretation of results is as follows:

\subsubsection{The effect of the congestion charging}

The effect of the CC is captured by a dummy variable. This variable is found to be negatively associated with the weekly sales of JLOS and is statistically significantly different from zero at the 95\% confidence level. This is an indication that average weekly sales are decreased after the introduction of congestion charging if all other factors remain constant. The coefficient $(\theta)$ of the effect of the CC represented by a dummy variable is -0.0568 indicating that the relative effect on the average weekly sales of JLOS due to the presence of the CC is $100 *\{\exp (\theta)-1\}$, or $-5.5 \%$. In other words, the CC reduces the expected weekly sales of JLOS by $5.5 \%$ holding all other factors included in the model constant.

\subsubsection{The effect of the closure of the central line}

The effect of the closure of the CL is also captured by a dummy variable, which is found to be statistically different from zero at the $95 \%$ confidence level. The average weekly sales during the closure of the CL is about 7\% lower than during the non-closure period, if all other factors remain constant. However, the interaction effect of the closure of the CL and the CC could not be estimated as these two events overlapped significantly and are therefore highly correlated with each other. 


\subsubsection{Annual events}

It is found that various annual events, such as Easter, the July clearance sales, Christmas and the Christmas sales, affect retail activity as expected. These factors are statistically significant in the model at the 95\% confidence level with the expected signs.

\subsubsection{Effect of seasons and trend}

The method of dummy variables is used to remove the seasonal component from the time series of weekly sales at JLOS. The month of February is taken as the base month in the model. The results show that only differential coefficients associated with the October, November and December are statistically significant at the $95 \%$ confidence level. Thus one may conclude that there are some seasonal factors operating in those months.

The trend term is taken as a continuous function of cumulative weeks starting with $t=1$ and ending with $t=205$. Categorical variables for the year (2000, 2001, 2002 and 2004) cannot be taken as the trend since the variable for 2003 is highly correlated with the dummy variable for the CC. However, the continuous trend function is found to be statistically significant at the $95 \%$ confidence level with the positive sign. This suggests that average weekly sales at JLOS are increasing over time although the coefficient is very low. 


\subsubsection{All other factors}

As mentioned earlier, GDP is not included in the model since it is highly correlated with the trend. Instead, an exchange rate $(£ / \$)$ is included and found to be statistically insignificant. The number of overseas visitors to the UK is also included in the model and found to be statistically insignificant. This is not surprising as JLOS has very few customers who are tourists from overseas. Further, the consumer price index (CPI) for furniture and household items was included and also found to be statistically insignificant.

\subsection{Results for all other branches: time series model}

It is found that a loglinear model with an AR(1) disturbance is also appropriate for modeling weekly sales of other JL branches. However, the linear regression model is not rejected in case of JLB and JL Brent Cross. The loglinear model is chosen for consistency. The results are also shown in Table 2 (the constants have been omitted to preserve confidentiality).

The effect of the CC on the weekly sales of JLB is found to be statistically significant with a positive sign, suggesting that the CC is associated with a $6.7 \%$ increase in weekly sales at JLB holding all other factors included in the model constant. The coefficient of the trend variable for JLB is very high compared to other branches, indicating that weekly sales at this store are increasing more rapidly compared to other stores. The exchange rate is found to be significantly different from zero for the JLB store, suggesting that if the UK Pound ( $£$ ) became stronger against US Dollar (\$) then weekly sales would increase. The CPI is also found to be statistically 
significant and to have a positive association with the weekly sales. The seasonal effect for JLB is found to be the same as for JLOS.

The effect of the CC on other branches is statistically insignificant. The association of all other variables with the weekly sales is found to be the same as for JLOS, except for the 'Easter' effect, which is found to be statistically insignificant for the other stores.

\subsection{Results: panel model}

A random effects loglinear model with an AR(1) disturbance is used to analysis the weekly sales of all JL branches in and around London. Several models are estimated in order to test for the trend in weekly sales of JLB. The results are presented in Table 3 (the constants have been omitted to preserve confidentiality of the sales data). The overall $R^{2}$ is found to be 0.95 , which is very satisfactory in terms of model goodness-of-fit.

\section{$<<$ Table 3 about here $>>$}

\subsubsection{Effect of trend}

A trend variable is included as a categorical dummy for years (2000, 2001, 2002 and 2003). Model A presumes an identical trend across the branches. Model B assumes a general trend across the branches as well as a separate trend for JLB. However, one trend variable 
(yr2003*Bluewater) for Bluewater is highly correlated with the dummy variable for the effect of the CC (CC_Bluewater). Therefore, model C is estimated excluding the effect of the CC on JLB.

\subsubsection{Effect of the congestion charging and the closure of the central line}

It can be seen that the effect of the CC on JLB in Model A is highly statistically significant with a coefficient of 0.111 . This is especially high when compared to the JLB model presented in Table 2. However, this variable becomes insignificant in both model B and model C when a separate trend is assumed for JLB. It can also be seen that other variables included in the model are of the same order of magnitude and signs across models A, B and C. It is also noticeable that the values of the coefficients of the trend variables for JLB are generally somewhat higher when compared to the coefficients of the trend variables for all other branches. This suggests that the trend variable 'yr2003*Bluewater' in Model C is captured by the effect of the CC on Bluewater as estimated in Model A.

The rest of the results are interpreted based on Model C in which there is no problem of multicollinearity. The effect of the CC on JLOS is found to be statistically significant with a negative sign. This is consistent with the JLOS model presented in Table 2. The value of the coefficient is now -0.086 meaning that the expected weekly sales of JLOS fall by $8.2 \%$ following the introduction of the CC holding all other factors included in the model constant.

The dummy variable representing the effect of the closure of the CL on the weekly sales of JLOS is also found to be significantly different from zero at the $95 \%$ confidence interval. This is consistent with the results presented in Table 2. However, the coefficient value is now -0.108 
which means that the average weekly sales during the closure of the CL are about $10.2 \%$ lower than during the non-closure period if all other factors remain constant.

The CC does not appear to have any effects on the weekly sales of JL Kingston and JL Brent Cross. This is also consistent with the findings in Table 2.

\subsubsection{Variation of weekly sales across branches}

The location of the JL branches is found to be associated with the weekly sales as expected. This is examined by a categorical variable, spatial variation, relative to JL Watford. JLOS shows the highest coefficient value followed by JL Brent Cross, JLB and JL Kingston.

\subsubsection{Annual and seasonal variation}

All annual events are found to be statistically significant at the $95 \%$ confidence level. The 'July Clearance sales' variables is found to be the most effective followed by 'Christmas sales' and then 'Easter sales'. This is consistent with the results presented in Table 2.

\section{Conclusions}

The aim of the sales data analysis was to investigate whether the introduction of the CC on the $17^{\text {th }}$ February 2003 in Central London had a significant impact on sales at the JLOS store. Descriptive analysis, forecasting methods and econometric models were used to estimate the impact of the CC. 
Descriptive analyses of sales data revealed that the weekly sales at the JLOS store in the trading year 2003 was generally weaker than in 2002, both in terms of revenue and number of transactions. There was a temporary increase in the revenue per transaction, which coincided with the period when the CL was most disrupted following the Chancery Lane incident on the $25^{\text {th }}$ of January 2003.

Forecasting models which were able to take into account trend and seasonal variation were used to fit weekly sales from $30^{\text {th }}$ January 2000 to $19^{\text {th }}$ January 2003. The fitted models were then used to forecast weekly sales for the trading year 2003. Both forecasting methods showed that the actual sales of the JLOS store matched the predicted sales up to $19^{\text {th }}$ January 2003; thereafter actual sales fall consistently below predicted sales. For the JLB store, however, the predicted sales are consistent with the actual sales for the whole time series.

Econometric models were used to identify the impact of a number of factors which were thought to be responsible for the overall reduction in sales at JLOS in 2003. These factors include the introduction of the CC, the closure of the CL, general economic conditions (GDP, foreign exchange rate, etc), the numbers of foreign tourists, price movements (CPI), the Iraq war, trend and seasonality. A loglinear model fitted to the JLOS store showed that the CC reduces the expected weekly sales of JLOS by 5.52\% holding all other factors included in the model constant. This is consistent with the forecasting models. A similar model fitted to the JLB store suggested that the introduction of the CC is associated with a $6.67 \%$ increase in weekly sales at JLB holding all other factors included in the model constant. Since the forecasting models indicated that there was no significant deviation between actual sales and predicted sales at the 
JLB in 2003, clarification was sought for this finding. A random effects panel data model was used to further investigate the association of sales and a number of factors. The results suggested that the expected weekly sales of JLOS fall by $8.21 \%$ following the introduction of the CC. The results also indicated that the increase of sales at Bluewater in 2003 was due to trend rather than any other factors included in the model.

It would be interesting to extend the analysis to other stores, as the impact of the congestion charge is unlikely to be evenly distributed across the retail sector. For stores that are affected, it is anticipated that the impact of the congestion charge will diminish with time, as both shoppers and shops adapt. Sunday opening is one example of adaptation, which may be accompanied by changes in product mix sold. The results presented in this paper lend support to the view that congestion charging can have profound implications for certain parts of the retail sector.

\section{Acknowledgements}

The authors would like to thank Daniel Graham, Stephen Hess, Bob Noland and Robin North (all of the Centre for Transport Studies at Imperial College London) as well as Nigel Brotherton and Jane Rose (both of the John Lewis Partnership) for their important contribution to the work.

\section{References}

Bonsall, 2000, Legislating for Modal Shift: Background to the UK's New Transport Act. Transport Policy, 17 (3), 179-184. 
Carmel, A., 2003, The causes of recent poor retail sales performance in central London, London's Economy Today, 11, 10-15.

Chatfield, C., 1996, The Analysis of Time Series: an Introduction, $5^{\text {th }}$ Edition, London: Chapman Chatterjee, S., Hadi, A.S., Price, B., 2000, Regression analysis by example. $3^{\text {rd }}$ Edition. New York: John Wiley \& Sons.

London First, 2004, Press Release, available at: http://www.london-

first.co.uk/press_centre/newsreleasedetail.asp?L2=106\&NewsReleaseId=2317, updated 16

February 2004, accessed July 15, 2004.

Mackinnon J.G., White, H., Davidson, R., 1983, Tests for Model Specification in the Presence of Alternative Hypothesis: Some Further Results. Journal of Econometrics, 21, 53-70.

Mills, T. C., 1997, The Econometric Modelling of Financial Time Series. Cambridge University Press.

Park, R.E., 1966, Estimation with Heteroskedasticity Error Terms. Econometrica, 44(3), 461465.

Quddus, M.A., Carmel, A., Bell, M.G.H., 2006, The impact of the London congestion charge on retail: the London experience, Accepted for publication in Journal of Transport Economics and Policy. 
Ramsey, J.B., 1969, Tests for Specification Errors in Classical Linear Least Squares Regression Aanalysis. Journal of the Royal Statistical Society, series B, 31, 50-371.

The Office of National Statistics, ONS. The National Statistics Homepage.

www.statistics.gov.uk. Accessed January 15, 2003.

Transport for London (TfL), Congestion charging: Six Months On. Available on the internet at: http://www.tfl.gov.uk. Accessed January 10, 2003.

Schmöcker, J-D., Fonzone, A., Quddus, M. and M.G.H. Bell, 2004, Changes in the Frequency of shopping trips in response to a congestion charge. Transport Policy, 13 (3), 217 - 228.

Winsor-Cundell, E., 2003, The Retail Survey: Impact of the Congestion Charge on the Retail Sector, London Chamber of Commerce and Industry. Available on the internet at: http://www.londonchamber.co.uk. Accessed July 15, 2004.

, T., 2000, Road User Charging and Business Performance: Identifying the Processes of Economic Change. Transport Policy, 9 (3), 117-131. 


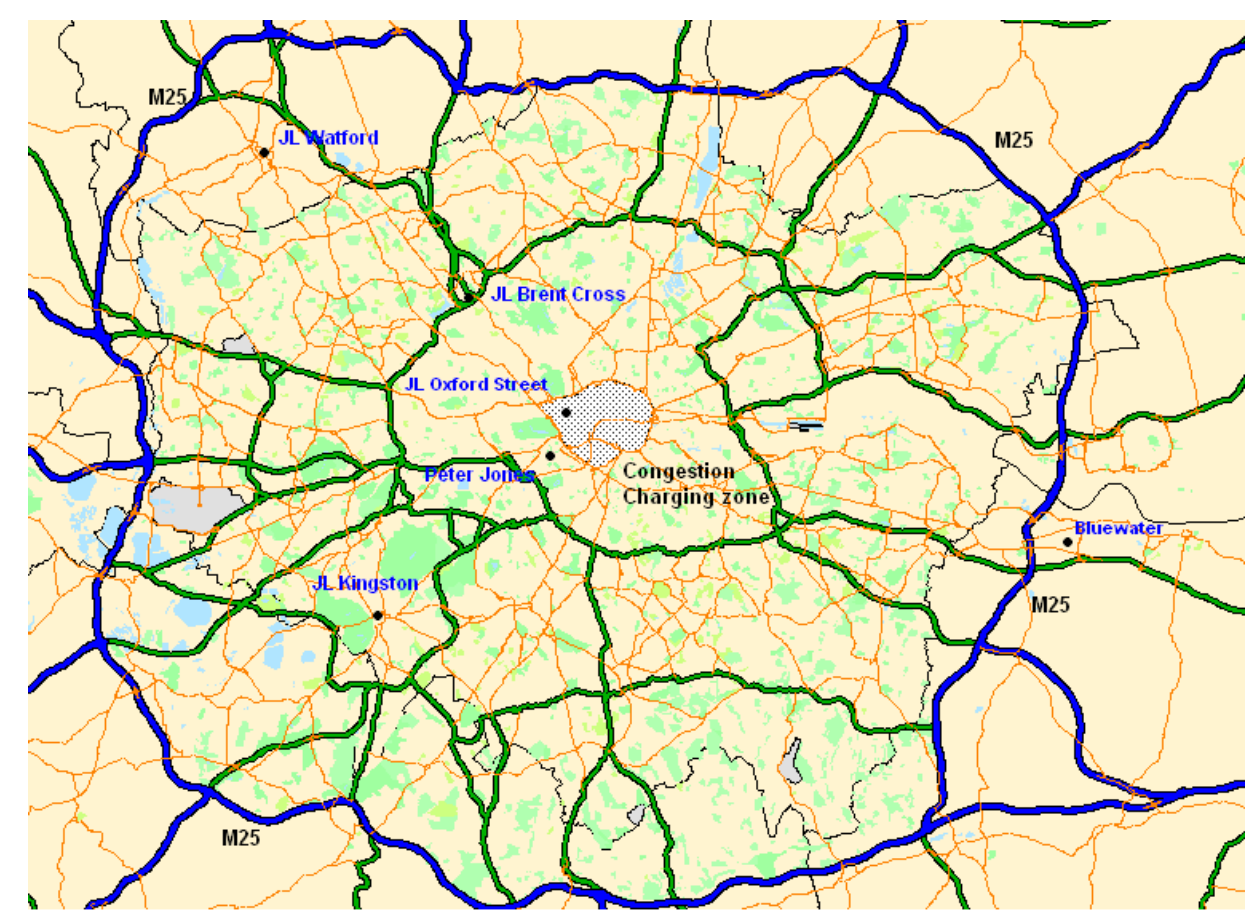

FIGURE 1 Location of all JL branches and the charging zone in the London area. 


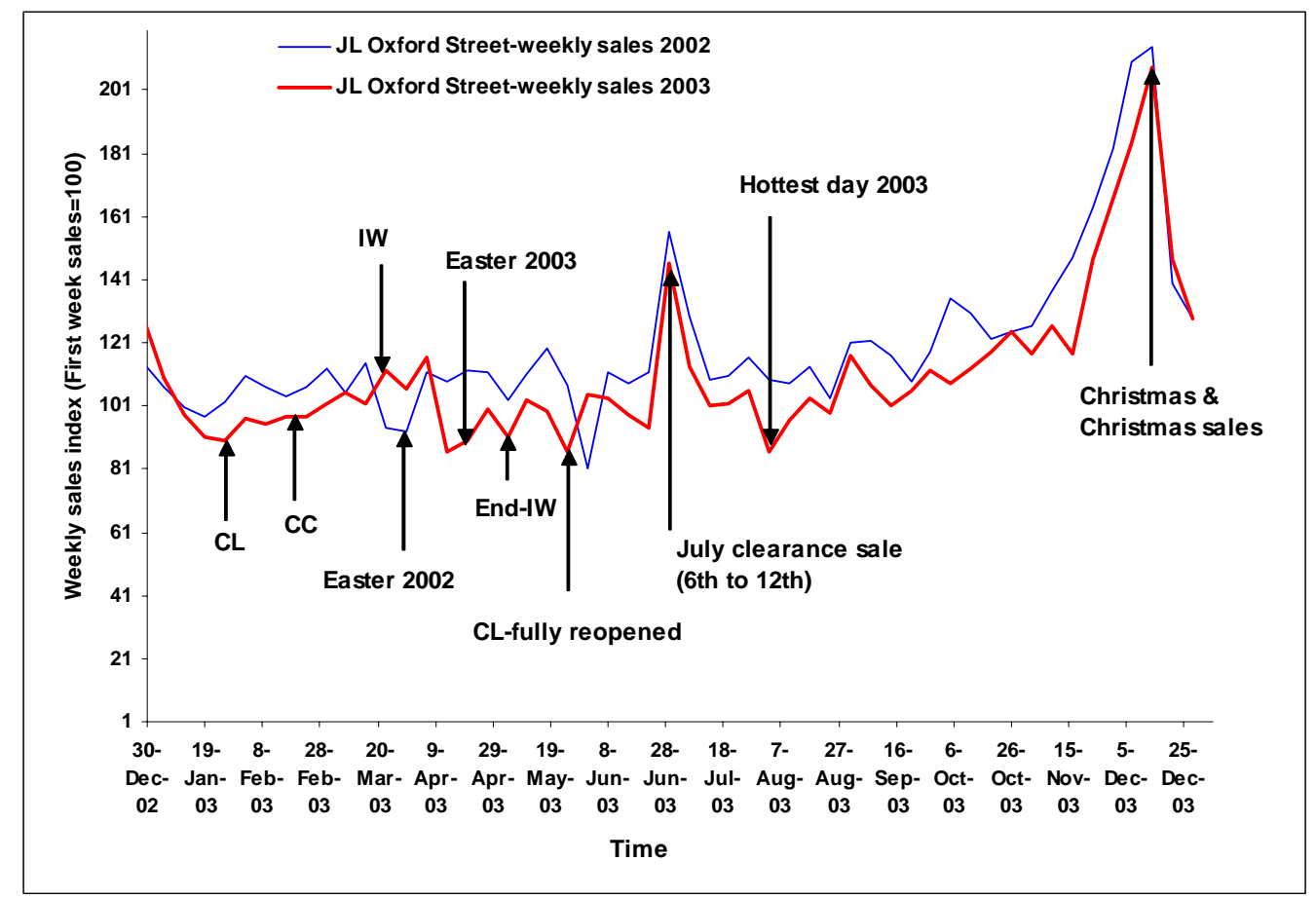

FIGURE 2 Time plot of JLOS weekly sales for 2003 and 2002. 


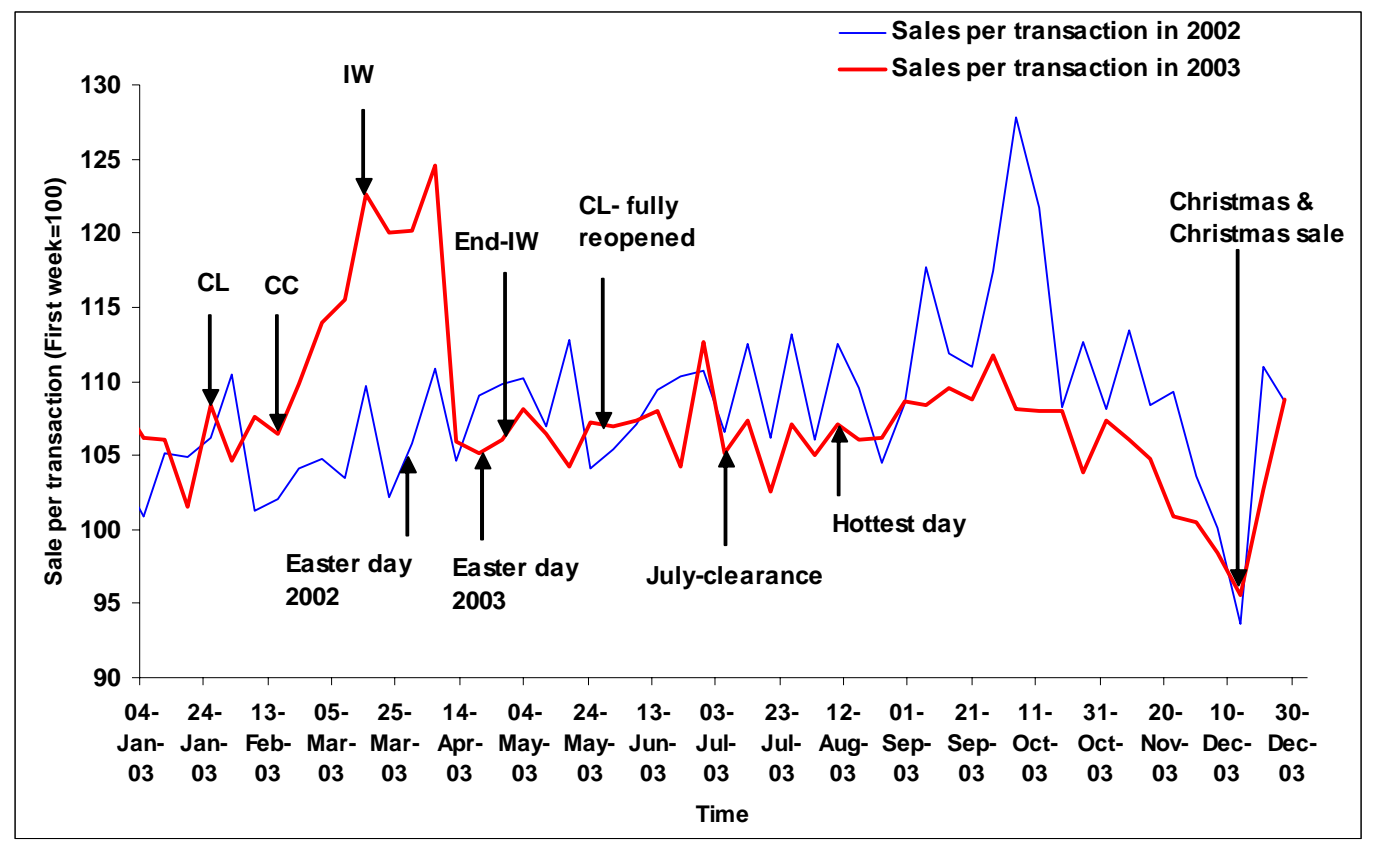

FIGURE 3 Time plot of JLOS's weekly sale per transaction for 2002 and 2003. 


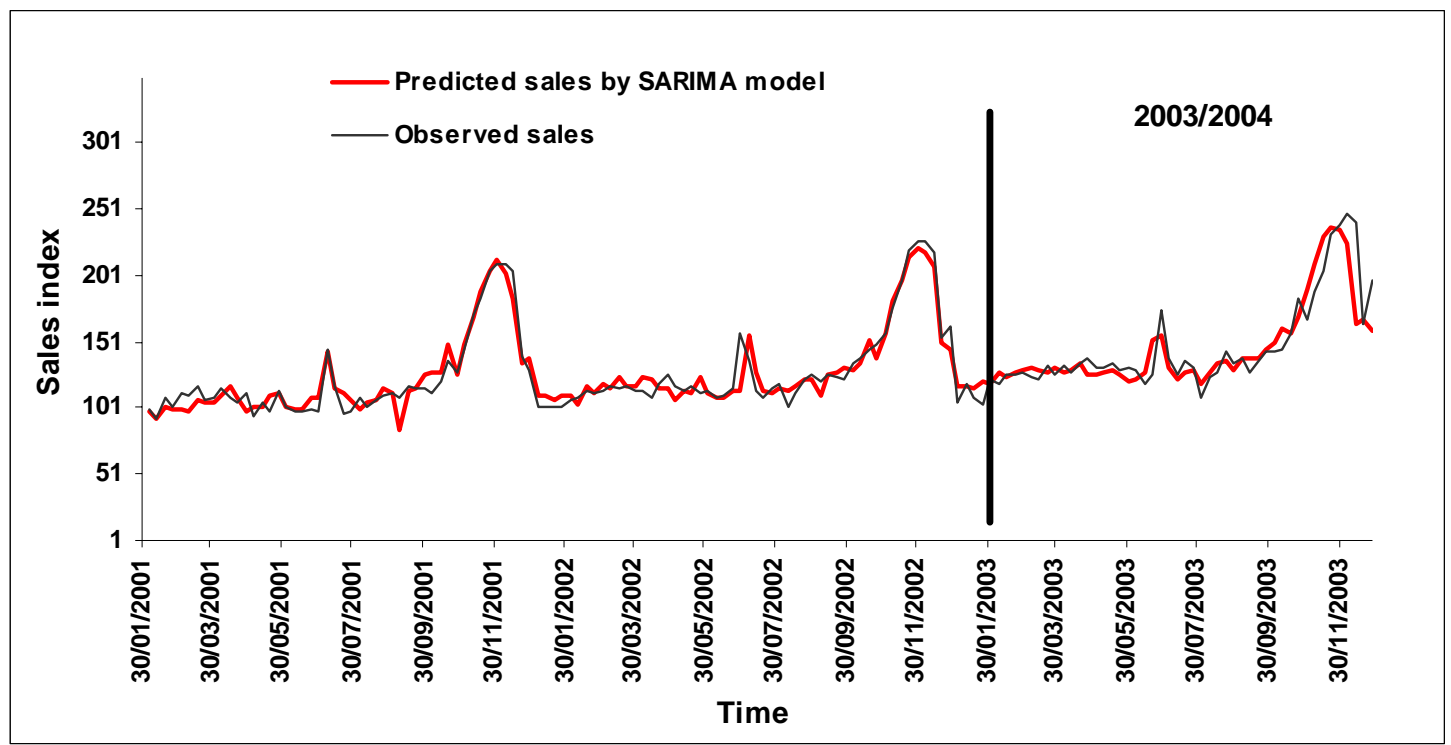

FIGURE 4 Comparison of observed and predicted weekly sales at JLB. 


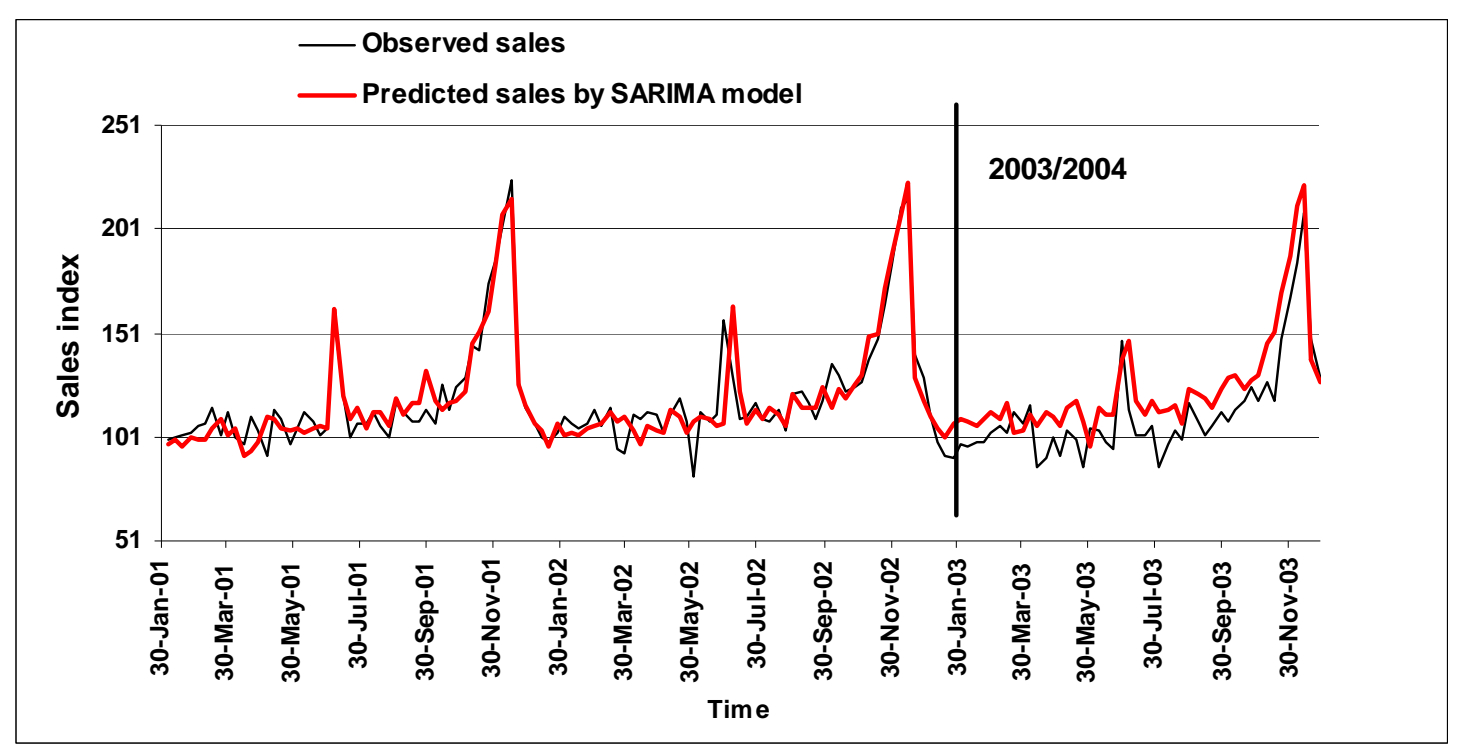

FIGURE 5 Comparison of observed and predicted weekly sales at JLOS 2003. 


\section{TABLE 1 Summary Statistics of Explanatory Variables Considered in the Models}

\begin{tabular}{|c|c|c|c|c|}
\hline Explanatory Variable & Type & Minimum & Maximum & Mean \\
\hline The effect of the congestion charge & Dummy & 0 & 1 & 0.2293 \\
\hline The effect of the closure of the central line & Dummy & 0 & 1 & 0.0976 \\
\hline Gross domestic product (GDP) for the UK & Continuous & 99.00 & 107.40 & 103.08 \\
\hline Exchange rate $(£ / \$)$ & Continuous & 1.390 & 1.827 & 1.5227 \\
\hline The effect of the Iraq War (IW) & Dummy & 0.000 & 1.000 & 0.0290 \\
\hline Number of overseas visitors to the UK & Continuous & 1261 & 2902 & 2029 \\
\hline \multicolumn{5}{|l|}{ Consumer Price Index (CPI) } \\
\hline Clothing and footwear & Continuous & 65.500 & 84.700 & 74.110 \\
\hline Furniture and household equipments & Continuous & 96.700 & 100.900 & 98.401 \\
\hline \multicolumn{5}{|l|}{ Control for the higher weeks' sale e.g., } \\
\hline Easter sale & Dummy & 0 & 1 & 0.0195 \\
\hline July-Clearance sale & Dummy & 0 & 1 & 0.0195 \\
\hline Christmas sale & Dummy & 0 & 1 & 0.0293 \\
\hline \multicolumn{5}{|l|}{ Control for monthly effect (seasonal effect) } \\
\hline January & Dummy & 0 & 1 & 0.0634 \\
\hline February & Dummy & 0 & 1 & 0.0780 \\
\hline March & Dummy & 0 & 1 & 0.0878 \\
\hline April & Dummy & 0 & 1 & 0.0878 \\
\hline May & Dummy & 0 & 1 & 0.0780 \\
\hline June & Dummy & 0 & 1 & 0.0878 \\
\hline July & Dummy & 0 & 1 & 0.0878 \\
\hline August & Dummy & 0 & 1 & 0.0829 \\
\hline September & Dummy & 0 & 1 & 0.0878 \\
\hline October & Dummy & 0 & 1 & 0.0829 \\
\hline November & Dummy & 0 & 1 & 0.0829 \\
\hline December & Dummy & 0 & 1 & 0.0927 \\
\hline \multicolumn{5}{|l|}{ Control for trend } \\
\hline Year 2000 & Dummy & 0 & 1 & 0.2537 \\
\hline Year 2001 & Dummy & 0 & 1 & 0.2537 \\
\hline Year 2002 & Dummy & 0 & 1 & 0.2537 \\
\hline Year 2003 & Dummy & 0 & 1 & 0.2390 \\
\hline Cummulative week & Continuous & 1 & 205 & 103.0000 \\
\hline
\end{tabular}


TABLE 2 Model Estimation Results for Time Series Models

\begin{tabular}{|c|c|c|c|c|c|c|c|c|c|c|}
\hline \multirow{2}{*}{$\begin{array}{c}\text { Model: Loglinear with } \\
\qquad A R(1)\end{array}$} & \multicolumn{2}{|c|}{ JLOS } & \multicolumn{2}{|c|}{ JLB } & \multicolumn{2}{|c|}{ Kingston } & \multicolumn{2}{|c|}{ Brentcross } & \multicolumn{2}{|c|}{ Watford } \\
\hline & Coef. & $t$-stat & Coef. & $t$-stat & Coef. & $t$-stat & Coef. & $t$-stat & Coef. & $t$-stat \\
\hline Congestion charge & -0.057 & -2.38 & 0.065 & 2.37 & 0.037 & 1.62 & 0.031 & 1.39 & 0.001 & 0.04 \\
\hline Central line closure & -0.072 & -2.81 & - & - & - & - & - & - & - & - \\
\hline Log(exchange rate) & 0.090 & 0.53 & 0.601 & 3.1 & 0.556 & 3.45 & 0.194 & 1.24 & 0.440 & 2.6 \\
\hline Easter & 0.113 & 2.66 & -0.001 & -0.01 & 0.048 & 1.15 & 0.047 & 1.16 & 0.040 & 0.95 \\
\hline Log(visitors) & -0.025 & -0.25 & 0.006 & 0.05 & 0.087 & 0.94 & -0.070 & -0.78 & 0.048 & 0.5 \\
\hline log(CPI_furniture) & -1.667 & -0.97 & 4.272 & 2.21 & 1.825 & 1.14 & 2.953 & 1.9 & 2.167 & 1.31 \\
\hline Christmas & 0.261 & 6.52 & 0.080 & 1.69 & 0.157 & 4.04 & 0.166 & 4.36 & 0.148 & 3.72 \\
\hline Clearence & 0.359 & 8.02 & 0.301 & 5.56 & 0.305 & 6.92 & 0.376 & 8.69 & 0.372 & 8.36 \\
\hline January & 0.020 & 0.58 & 0.063 & 1.55 & 0.073 & 2.18 & 0.115 & 3.51 & 0.074 & 2.13 \\
\hline March & 0.070 & 1.48 & -0.017 & -0.32 & -0.001 & -0.03 & -0.015 & -0.35 & 0.010 & 0.22 \\
\hline April & 0.014 & 0.28 & 0.024 & 0.41 & -0.024 & -0.5 & 0.013 & 0.28 & 0.004 & 0.07 \\
\hline May & 0.066 & 1.17 & -0.036 & -0.57 & -0.005 & -0.1 & 0.014 & 0.27 & 0.011 & 0.19 \\
\hline June & 0.019 & 0.32 & -0.050 & -0.73 & -0.080 & -1.41 & 0.012 & 0.22 & -0.043 & -0.73 \\
\hline July & 0.054 & 0.79 & 0.053 & 0.67 & 0.008 & 0.13 & 0.159 & 2.52 & 0.035 & 0.52 \\
\hline August & 0.041 & 0.57 & -0.012 & -0.15 & -0.048 & -0.71 & 0.112 & 1.72 & -0.003 & -0.05 \\
\hline September & 0.095 & 1.72 & -0.013 & -0.21 & 0.038 & 0.73 & 0.099 & 1.96 & 0.044 & 0.8 \\
\hline October & 0.140 & 3.26 & 0.136 & 2.74 & 0.106 & 2.56 & 0.155 & 3.88 & 0.115 & 2.66 \\
\hline November & 0.262 & 6.15 & 0.331 & 6.68 & 0.285 & 6.95 & 0.212 & 5.35 & 0.314 & 7.35 \\
\hline December & 0.493 & 9.18 & 0.422 & 6.78 & 0.435 & 8.43 & 0.393 & 7.86 & 0.593 & 11.06 \\
\hline Log(cumweek) & 0.030 & 3.77 & 0.104 & 11.41 & 0.043 & 5.62 & 0.030 & 4.03 & 0.041 & 5.12 \\
\hline Constant & 9.3 & 1.1 & -19.7 & -2.2 & -8.8 & -1.2 & -12.5 & -1.7 & -10.5 & -1.4 \\
\hline Observations & 204 & 204 & 204 & 204 & 204 & 204 & 204 & 204 & 204 & \\
\hline R-square & 0.84 & & 0.88 & & 0.87 & & 0.84 & & 0.9 & \\
\hline Adjusted R-square & 0.82 & & 0.86 & & 0.86 & & 0.83 & & 0.88 & \\
\hline Autocorrelation coef. & -0.007 & & -0.047 & & -0.03 & & -0.043 & & 0.009 & \\
\hline Durbin-Watson test & 1.96 & & 1.99 & & 1.99 & & 2.01 & & 1.92 & \\
\hline
\end{tabular}


TABLE 3 Model Estimation Results for Panel Model

\begin{tabular}{|c|c|c|c|c|c|c|c|c|c|}
\hline \multicolumn{10}{|c|}{ Random Effect Loglinear Model with AR(1) Disturbance } \\
\hline \multirow{2}{*}{$\begin{array}{l}\text { All John Lewis Branches in and } \\
\text { around London }\end{array}$} & \multicolumn{3}{|c|}{ Model A } & \multicolumn{3}{|c|}{ Model B } & \multicolumn{3}{|c|}{$\begin{array}{l}\text { Model C } \\
\end{array}$} \\
\hline & Coef. & $t$-stat & $p$-value & Coef. & $t$-stat & $p$-value & Coef. & $t$-stat & $p$-value \\
\hline \multicolumn{10}{|l|}{ Control Variables } \\
\hline CC_Oxford & -0.091 & -2.06 & 0.04 & -0.085 & -2.08 & 0.04 & -0.086 & -2.08 & 0.04 \\
\hline CC_Blue water & 0.111 & 2.61 & 0.01 & 0.049 & 0.66 & 0.51 & \multicolumn{3}{|c|}{ Omitted due to correlation } \\
\hline CC_PeterJones & -0.039 & -0.92 & 0.36 & -0.025 & -0.64 & 0.52 & -0.026 & -0.66 & 0.51 \\
\hline CC_Kingston & 0.021 & 0.5 & 0.62 & 0.034 & 0.87 & 0.39 & 0.034 & 0.85 & 0.40 \\
\hline CC_Brent Cross & -0.035 & -0.82 & 0.41 & -0.025 & -0.63 & 0.53 & -0.026 & -0.65 & 0.52 \\
\hline CL_Oxford & -0.121 & -2.49 & 0.01 & -0.107 & -2.37 & 0.02 & -0.108 & -2.37 & 0.02 \\
\hline Log(visitors) & 0.055 & 0.79 & 0.43 & 0.071 & 1.08 & 0.28 & 0.072 & 1.08 & 0.28 \\
\hline $\log (\mathrm{HICP}$ _furniture) & 2.337 & 2.37 & 0.02 & 2.308 & 2.37 & 0.02 & 2.307 & 2.37 & 0.02 \\
\hline \multicolumn{10}{|l|}{ Spatial variation } \\
\hline Oxford_Street & 1.470 & 58.99 & 0.00 & 0.071 & 1.08 & 0.28 & 1.468 & 65.83 & 0.00 \\
\hline Peter Jones & 0.511 & 20.55 & 0.00 & 2.308 & 2.37 & 0.02 & 0.507 & 22.82 & 0.00 \\
\hline Brent Cross & 0.644 & 25.91 & 0.00 & 0.642 & 28.95 & 0.00 & 0.642 & 28.87 & 0.00 \\
\hline Kingston & 0.466 & 18.75 & 0.00 & 0.463 & 20.9 & 0.00 & 0.463 & 20.83 & 0.00 \\
\hline Blue Water & 0.469 & 18.88 & 0.00 & 0.372 & 11.28 & 0.00 & 0.372 & 11.24 & 0.00 \\
\hline Watford (Reference variable) & - & - & - & - & - & - & & & \\
\hline \multicolumn{10}{|l|}{ Annual events } \\
\hline Easter & 0.065 & 4.19 & 0.00 & 0.065 & 4.09 & 0.00 & 0.065 & 4.09 & 0.00 \\
\hline Clearance & 0.314 & 19.53 & 0.00 & 0.316 & 19.29 & 0.00 & 0.316 & 19.31 & 0.00 \\
\hline Christmas & 0.251 & 14.75 & 0.00 & 0.252 & 14.69 & 0.00 & 0.252 & 14.69 & 0.00 \\
\hline \multicolumn{10}{|l|}{ Seasonal effects } \\
\hline January & 0.149 & 6.52 & 0.00 & 0.151 & 6.82 & 0.00 & 0.152 & 6.90 & 0.00 \\
\hline February (Reference variable) & & & & - & - & - & & & \\
\hline March & -0.050 & -1.88 & 0.06 & -0.048 & -1.85 & 0.06 & -0.048 & -1.83 & 0.07 \\
\hline April & -0.064 & -1.96 & 0.05 & -0.062 & -1.96 & 0.05 & -0.062 & -1.94 & 0.05 \\
\hline May & -0.036 & -1.03 & 0.30 & -0.033 & -0.99 & 0.32 & -0.033 & -0.97 & 0.33 \\
\hline June & -0.083 & -2.09 & 0.04 & -0.081 & -2.1 & 0.04 & -0.080 & -2.09 & 0.04 \\
\hline July & 0.003 & 0.06 & 0.96 & 0.003 & 0.06 & 0.96 & 0.003 & 0.06 & 0.95 \\
\hline August & -0.011 & -0.22 & 0.83 & -0.017 & -0.35 & 0.73 & -0.016 & -0.34 & 0.74 \\
\hline September & 0.032 & 0.88 & 0.38 & 0.032 & 0.93 & 0.35 & 0.033 & 0.95 & 0.34 \\
\hline October & 0.123 & 3.99 & 0.00 & 0.127 & 4.32 & 0.00 & 0.127 & 4.34 & 0.00 \\
\hline November & 0.185 & 6.69 & 0.00 & 0.202 & 7.57 & 0.00 & 0.202 & 7.60 & 0.00 \\
\hline December & 0.273 & 8.59 & 0.00 & 0.296 & 9.53 & 0.00 & 0.297 & 9.55 & 0.00 \\
\hline \multicolumn{10}{|l|}{ Trend effect } \\
\hline Year 2000 (Reference variable) & - & - & - & - & - & - & & & \\
\hline Year 2001 & 0.042 & 2.38 & 0.02 & 0.022 & 1.22 & 0.22 & 0.022 & 1.23 & 0.22 \\
\hline Year 2002 & 0.089 & 5.03 & 0.00 & 0.058 & 3.32 & 0.00 & 0.058 & 3.33 & 0.00 \\
\hline Year 2003 & 0.173 & 6.13 & 0.00 & 0.142 & 5.16 & 0.00 & 0.143 & 5.18 & 0.00 \\
\hline \multicolumn{10}{|l|}{ Separate trend for Blue Water } \\
\hline Yr2000*BlueWater & - & - & - & - & - & - & & & \\
\hline Yr2001*BlueWater & - & - & - & 0.112 & 2.74 & 0.01 & 0.112 & 2.74 & 0.01 \\
\hline Yr2002*BlueWater & - & - & - & 0.165 & 3.9 & 0.00 & 0.167 & 3.96 & 0.00 \\
\hline Yr2003*BlueWater & & & & 0.175 & 2.12 & 0.03 & 0.219 & 4.59 & 0.00 \\
\hline Constant & Omit & -2.39 & 0.02 & Omit & -2.42 & 0.02 & Omit & -2.42 & 0.02 \\
\hline Observations & 1230 & & & 1230 & & & 1230 & & \\
\hline Overall R-squared & 0.940 & & & 0.950 & & & 0.950 & & \\
\hline $\begin{array}{l}\text { Estimated Autocorrelation } \\
\text { Coefficent }\end{array}$ & 0.620 & & & 0.570 & & & 0.570 & & \\
\hline
\end{tabular}

